\title{
AN INVESTIGATION OF SOCIAL SKILLS AND LONELINESS LEVELS OF UNIVERSITY STUDENTS WITH RESPECT TO THEIR ATTACHMENT STYLES IN A SAMPLE OF TURKISH STUDENTS
}

\author{
M. Engin Deniz, Erdal hamarta, and Ramazan Ari \\ Selcuk University, Campus Konya, Turkey
}

This study investigated the effects of attachment styles of university students on their social skills and loneliness levels. Their social skill levels, loneliness levels and attachment styles were measured by the Social Skills Inventory, UCLA Loneliness Scale, and Relationships Scale Questionnaire respectively. To analyze data, $t$-test, correlation analysis, and regression analysis were employed. Emotional expressivity levels, emotional sensitivity levels, social control levels, and total social skill levels of female students were found to be significantly higher than those of male students. However, emotional control levels of male students were significantly higher than those of female students. A significant effect of attachment styles on loneliness and social skills was detected. Social skill levels of students who have secure attachment styles were found to be significantly higher than social skills levels of students who have insecure attachment styles. Average loneliness points of students who do not have a romantic relationship were found to be significantly higher than others. However, the average social skill points of those students were found to be significantly lower than others.

An individual's ability to have close relationships with others is one of the most important features of a healthy personality. Close relationships influence the personal and social development processes of individuals considerably. Although

M. Engin Deniz, Assistant Professor, Faculty of Technical Education, Selcuk University, Campus Konya, Turkey, Erdal Hamarta, Research Assistant, Faculty of Education, Selcuk University, Meram Konya, Turkey, and Ramazan Ari, Professor, Faculty of Occupational Education, Selcuk University, Campus Konya, Turkey.

Appreciation is due to all reviewers including: Enrico DiTommaso, $\mathrm{PhD}$, Department of Psychology, The University of New Brunswick, PO Box 5050, Saint John, NB, Canada E2L 4L5, Email: <rico@unbsj.ca>

Keywords: attachment styles, loneliness, romantic relationship, social skills, Turkey.

Please address correspondence and reprint requests to: $\mathrm{M}$. Engin Deniz, PhD, Assistant Professor, Selcuk University, Faculty of Technical Education, Department of Education, Campus 42075, Konya, Turkey. Phone: +90 332223 3327; Fax: +90 332241 2179; Email: <engindeniz@selcuk.edu.tr> 
the attachment theory of Bowlby was suggested to explain the emotional attachment between children and their parents, this attachment is an important element of individuals from the cradle to the grave (Bowlby, 1979).

An individual's initial attachment is established early in development with his/her primary caregiver(s). This relationship provides a cognitive framework that informs how an individual will perceive and interact with his/her environment beyond early childhood. When these attachment representations, or working models, are formed in affectionate and supportive environments, children will have a secure base from which to explore and master their environment. This positive frame of reference provides a sense of self-efficacy, thereby facilitating an adolescent's successful transition to young adulthood (DiTommaso, Brannen-McNulty, Ross, \& Burgess, 2003).

Attachment is behavior evoked by closeness to or alienation from a selected and/or distinguished individual. Existing literature shows that attachment behavior is not only a part of infancy but also is a part of childhood, adolescence, and adulthood. One of the main principles of the attachment theory is its continuity throughout the individual's lifelong journey (Bowlby, 1980). A direct support for the continuity of attachment styles is provided by the study of Waters Merrick, Treboux, Crowell, and Albersheim (2000). They provide strong evidence of similarities between attachment styles in infancy and attachment styles in adulthood.

Bartholomew and Horowitz (1991) proposed a model that is based on the attachment theory of Bowlby to explain attachment styles of adults. Based on the different views of self and others in relationships, they suggested two different internal working models and four different attachment styles. Individuals who are characterized as secure see themselves and others positively. These individuals are seen as having a intimate relationships and high self-esteem and they also trust others. Individuals who are classified as fearful are characterized as having low self-esteem and being socially avoidant. These individuals also have a negative view of themselves and others. Individuals who are classified as preoccupied are seen as having a negative view of themselves and a positive view of others. These individuals are characterized by high level dependencies. They try to earn the esteems of others and tend to control their interpersonal style. Individuals who are classified as dismissing are seen as having a positive view of themselves and a negative view of others. These individuals have high selfesteem and try to control their relationships. They have low ability to have intimate relationships and try to suppress their emotions. They not only do not trust others to help but also do not help others.

The preoccupied attachment style identified by Bartholomew and Horowitz (1991) is equivalent to the anxiety/ambivalence attachment style identified by Hazan and Shaver (1987). The avoidant attachment style of Hazan and Shaver 
was classified as fearful and dismissing attachment styles in the model of Bartholomew and Horowitz (1991).

Although no agreement on the definition of loneliness is available, it can be defined as an emotion which is evoked when the social relationships of an individual are extremely deficient both qualitatively and quantitatively (Peplau \& Perlman, 1982). Loneliness is composed of negative emotions such as trouble and distress (Jones, Freemon, \& Goswick, 1981; Russell, Peplau \& Cutrona, 1980). Weiss (1974) pointed out the existence of a link between attachment theory and loneliness. Weiss (1989) defined loneliness as an anxiety situation which arises when the individual is separated from his/her attachment figure.

Working models and attachment styles provide a point of view to explain the situations of chronically lonely individuals. Shaver and Hazan (1989) stated that both babies and adults will experience separation grief if they separate from their attachment figures. Working models also provide some emotional schemes on individuals' skills and their expectations related to attachment styles. Individuals who are not classified as secure have a negative view of their attachment figures, while individuals who are classified as secure have figures that have secure interests. There are several studies which indicate that lonely individuals are classified as insecure. The study by Nurmi, Toivonen, Salmela-Aro, and Eronen (1997) showed that pessimistic and avoidant emotional strategies of individuals are related to their loneliness for more than one year.

Attachment styles of individuals not only have an effect on the existence of loneliness emotions but also are an important part of social skills development. Riggio (1986) proposed a model that assesses emotional and social skills, as each being a set of particular interpersonal abilities which facilitate social interaction. Emotional and social skills are measured through expressivity, control, and sensitivity.

Emotional communication skills, especially the ability to send emotional signals are measured by Emotional Expressivity (EE). This frame is also the precise expression skill of emotional situations in interpersonal interactions. Emotionally expressive individuals are very cheerful and they can impress others. Emotionally Sensitivity (ES) is defined as the ability of perceiving and interpreting other individuals' nonverbal communications. Emotionally sensitive individuals can precisely interpret the emotional signals of others. Emotional Control (EC) is the ability to arrange and control the emotional and nonverbal responses of others. Social Expressivity (SE) refers to the ability of verbal expressivity and establishing/maintaining social communications. Socially expressive individuals can easily start and manage social and other conversations. Social Sensitivity (SS) is defined as the ability to interpret verbal communications (signals). Socially sensitive individuals care about the social norms and show conscious behaviors. Social Control (SC) refers to the ability of 
role-playing and social self-presentation. People who have improved social control abilities are characterized by appropriate behaviors in social ambiences and by having high self-esteem (Riggio, 1986; Riggio, 1999).

Attachment style is an important factor that affects interpersonal relationships, while loneliness is an indicator of adaptation difficulties in such relationships. In the current study, it has been assumed that the following conditions will be met: (i) there is a relationship between social skills and loneliness; (ii) social skill levels of students who have secure attachment styles are higher than social skills levels of students who have insecure attachment styles; (iii) loneliness levels of students who have no romantic relationships are significantly higher than the loneliness levels of others. According to these theoretical postulations, the relationships among attachment styles, loneliness and social skills are the main concerns of this research.

This study aimed to investigate the effects of attachment styles and gender on loneliness and social skills. In this respect, the following questions were to be answered in this study:

1. Are total social skill points of students significantly different from the average subscale points of students with respect to gender?

2. Do average loneliness points of students differentiate with respect to gender?

3. Do attachment styles of students significantly affect the average social skill and loneliness points?

4. Do social skill and loneliness levels of students differentiate with respect to the existence of a romantic relationship?

\section{METHOD}

\section{Participants}

In this study, the general search model was adopted. The sample set of the research was taken from several faculties of Selcuk University (Konya/Turkey) by the random set sampling method. The participants were 383 students (216 male, 167 female) who participated in the study voluntarily. The mean age of the participants was 20.12 years with a standard deviation of 1.90 years.

\section{INSTRUMENTS}

Social Skills Inventory (SSI) The SSI developed by Riggio (1986), revised by Riggio (1989), and adapted to Turkish participants by Yuiksel (1997) was used to obtain data related to the social skills of participants. The SSI is a 90-item Likerttype inventory of self-report to measure basic social skills. The SSI consists of six subscales. Reliability studies of SSI were performed by the Retest Method and the reliability coefficients for subscales varied between .80 and .89 . The 
Cronbach's Alpha Reliability Coefficient of the social skill subscales varied between .56 and .82 . The parallel form validity of the SSI was tested with the Self-Monitoring Scale (SMS) which was adapted to Turkish by Bacanlı (1997). The correlation coefficients among SSI subscales and SMS varied between -.21 and .57 .

University of California Los Angeles Loneliness Scale (UCLA) The UCLA developed by Russell, Peplau, and Ferguson (1978), revised by Russell, Peplau, and Cutrona (1980), and adapted to Turkish participants by Demir (1990) was used to measure the loneliness levels of students. The UCLA is a 20-item Likerttype scale to measure general loneliness levels of participants.

The reliability coefficient of the UCLA was calculated as .94 by the Retest Method and the Cronbach's Alpha Reliability Coefficient of the UCLA was found to be .96 . The parallel form validity of the UCLA was tested with the Beck Depression Inventory and the correlation coefficient was found to be .77 (Demir, 1990).

Relationships Scales Questionnaire (RSQ) The RSQ developed by Griffin and Bartholomew (1994) and adapted to Turkish participants by Sümer and Güngör (1999) was used to determine the attachment styles of students. This inventory is a 17-item Likert-type scale to measure four different attachment styles (secure, dismissing, fearful, and preoccupied). The reliability coefficients of the scale were calculated by the Retest Method and varied between .54 and .78 . The parallel form validity of this scale was tested with the Relationship Questionnaire (Bartholomew \& Horowitz, 1991) and the correlation coefficients varied between .49 and .61 .

\section{Procedure}

Regression analysis, $t$-test, and Pearson correlation coefficients were employed to analyze the data obtained by inventories used in the research. The SPSS 10.0 package was used in the analysis of the data.

\section{RESULTS}

Subproblems of the research and results of the statistical analysis performed for these subproblems are given below:

\section{Comparison of Social Skill LeVels and Loneliness Levels of Students WITH RESPECT TO GENDER}

The social skill levels and loneliness levels of university students were compared with respect to gender by $t$-test. A summary of statistics and their significances are given in Table 1. 
TABLE 1

Comparison of Social Skill Levels and Loneliness Levels of Students with Respect to GeNDER

\begin{tabular}{lllllc}
\hline Dependent variable & Gender & $N$ & $M$ & $S D$ & $t$ \\
\hline Loneliness & Female & 216 & 32.12 & 8.54 & $-1.993^{*}$ \\
& Male & 167 & 33.94 & 9.14 & \\
Emotional Expressivity & Female & 216 & 47.06 & 8.46 & $2.721^{* *}$ \\
& Male & 167 & 44.90 & 7.08 & \\
Emotional Sensitivity & Female & 216 & 52.74 & 8.33 & $3.923^{* * *}$ \\
& Male & 167 & 49.43 & 8.08 & \\
Emotional Control & Female & 216 & 38.84 & 8.10 & $-3.701^{* * *}$ \\
Social Expressivity & Male & 167 & 41.79 & 7.43 & \\
& Female & 216 & 46.08 & 9.70 & .126 \\
Social Sensitivity & Male & 167 & 45.96 & 9.02 & \\
& Female & 216 & 49.50 & 9.04 & 1.450 \\
Social Control & Male & 167 & 48.25 & 7.81 & \\
& Female & 216 & 53.36 & 9.91 & $2.311^{*}$ \\
& Male & 167 & 50.95 & 10.29 & \\
\hline
\end{tabular}

${ }^{*} p<.05{ }^{* *} p<.01{ }^{* * *} p<.001$

As shown in Table 1, loneliness levels of male students are higher than loneliness levels of female students, with a significance level of .05. Emotional expressivity, emotional sensitivity, and social control levels of female students were found to be significantly higher than those of male students, with a significance level of .05 . Average emotional control subscale points of male students were found to be significantly higher than those of female students, with a significance level of .05 . No significant difference between male and female students with respect to social expressivity and social sensitivity levels was detected.

\section{Comparison of Social Skill and Loneliness Levels of Students with Respect to ATtachment Styles}

The relationships among attachment styles, loneliness levels, and social skill levels of students are given in Table 2. Results show a negative relationship between secure attachment style and loneliness. Loneliness was found to be positively correlated to dismissing, fearful, and preoccupied attachment styles, with a significance level of .05 . Secure attachment style was found to be positively correlated with emotional expressivity, social expressivity and social control; and negatively correlated with social sensitivity $(p<.05)$. A negative relationship between dismissing attachment style and emotional expressivity was also found $(p<.05)$. Fearful attachment style was found to be negatively correlated to emotional expressivity, social expressivity, and social control; positively correlated to social sensitivity. Preoccupied attachment style was 
found to be positively correlated to social sensitivity and negatively correlated with social control.

TABLE 2

Correlations among AtTachment Styles, Loneliness, and Social Skills

\begin{tabular}{lcllllll}
\hline Attachment & Loneliness & EE & ES & EC & SE & SS & SC \\
\hline Secure & $-.243^{* * *}$ & $.203^{* * *}$ & .054 & .040 & $.230^{* * * *}$ & $-.216^{* * *}$ & $.249^{* * *}$ \\
Dismissing & $.128^{* *}$ & $-.115^{*}$ & .006 & .094 & -.062 & .024 & -.099 \\
Fearful & $.226^{* * *}$ & $-.130^{*}$ & .062 & -.079 & $-.122^{*}$ & $.247^{* * *}$ & $-.222^{* * *}$ \\
Preoccupied & $.160^{* *}$ & .037 & .065 & -.015 & .030 & $.274^{* * *}$ & $-.146^{* *}$ \\
\hline
\end{tabular}

${ }^{*} p<.05{ }^{* *} p<.01^{* * *} p<.001$

A multiple regression analysis was performed to determine the effects of attachment styles on loneliness. Results given in Table 3 show that attachment styles have a significant effect on loneliness and explain $11.9 \%$ of loneliness variance $[p<.0001 ; F=12.734]$. The loneliness levels of students who have secure attachment styles were found to be lower than loneliness levels of students who have fearful, dismissing and preoccupied attachment styles.

TABLE 3

EXPLANATION OF LONELINESS BY ATTACHMENT STYLES

\begin{tabular}{lclll}
\hline Model & $R^{2}$ & $F$ & Attachment styles & $t$ \\
\hline Independent variables: & & & & \\
Attachment styles & & & & \\
(secure, fearful, dismissing, preoccupied) & .119 & $12.734^{* * * *}$ & Secure & $-3.871^{* * *}$ \\
& & & Fearful & $2.297^{*}$ \\
& & & Dismissing & $2.379^{*}$ \\
& & & Preoccupied & $3.533^{* * *}$
\end{tabular}

Dependent variable: Loneliness

${ }^{*} p<.05{ }^{* * *} p<.001$

The effects of attachment styles on social skills were examined by a multiple variable regression analysis and results are given in Table 4 . Results show that emotional expressivity, social expressivity, social sensitivity, and social control could be explained by attachment styles. Results also show that attachment styles do not have a significant effect on either emotional sensitivity or emotional control $[F=1.293(p>.05)$ and $F=1.834(p>.05)$ respectively]. Attachment styles explain $5.4 \%$ of emotional expressivity variance, $5.7 \%$ of social expressivity variance, $15.1 \%$ of social sensitivity variance, and $11.0 \%$ of social control variance. As shown in Table 4, high levels of emotional expressivity, social expressivity, and social control are related to the secure attachment style. High levels of social sensitivity are related to fearful and preoccupied attachment 
styles, while lower levels are related to the secure attachment style. Low levels of social control are also related to fearful and preoccupied attachment styles.

TABLE 4

Explanations of Social Skills by AtTachment Styles

\begin{tabular}{lcclc}
\hline Dependent variable & $R^{2}$ & $F$ & Independent variables & $t$ \\
\hline Emotional Expressivity & 0.054 & $5.444^{* * *}$ & Secure & $3.364^{* * *}$ \\
& & & Dismissing & -1.794 \\
& & & Fearful & -.926 \\
& & & Preoccupied & .435 \\
\hline Emotional Sensitivity & 0.013 & 1.293 & & \\
\hline Emotional Control & 0.019 & 1.834 & & \\
\hline Social Expressivity & 0.057 & $5.730^{* * *}$ & Secure & \\
& & & Dismissing & $3.985^{* * *}$ \\
& & & Fearful & -.779 \\
Social Sensitivity & & & Preoccupied & -.773 \\
& \multirow{2}{*}{0.151} & $16.835^{* * *}$ & Secure & .421 \\
& & & Dismissing & $-3.255^{* * *}$ \\
& & & Fearful & .438 \\
Social Control & & & Preoccupied & $3.207^{* * *}$ \\
& \multirow{2}{*}{0.110} & $11.386^{* * *}$ & Secure & $5.608^{* * *}$ \\
& & & Dismissing & $3.997^{* * *}$ \\
& & & Fearful & -1.720 \\
& & & Preoccupied & $-2.304^{* *}$ \\
& & & & $-3.152^{* * *}$ \\
\hline
\end{tabular}

${ }^{*} p<.05{ }^{* *} p<.01{ }^{* * *} p<.001$

\section{Loneliness Levels and Social Skill Levels of Students with Respect To the Existence of Romantic Relationships}

The loneliness levels and social skill levels of Turkish university students were examined by means of romantic relationship existence, and results are given in Table 5. Results show that loneliness levels of students who do not have a romantic relationship are higher than the loneliness levels of students who do have a romantic relationship. Results also show that emotional sensitivity, emotional expressivity, social expressivity, and social control levels of students who have a romantic relationship are significantly higher than those of others. 
TABLE 5

Comparison of Loneliness Levels and Social SKILl Levels of Students wTth ReSPeCt to THE EXISTENCE OF A ROMANTIC RELATIONSHIP

\begin{tabular}{lccccc}
\hline Dependent variable & Romantic relationship? & $N$ & $M$ & $S D$ & $t$ \\
\hline Loneliness & yes & 152 & 31.27 & 7.14 & $-3.165^{* *}$ \\
Emotional Expressivity & no & 231 & 33.99 & 9.66 & \\
& yes & 152 & 47.25 & 8.58 & $2.208^{*}$ \\
Emotional Sensitivity & no & 231 & 45.37 & 7.43 & \\
& yes & 152 & 52.90 & 8.61 & $3.033^{* *}$ \\
Emotional Control & no & 231 & 50.24 & 8.06 & \\
Social Expressivity & yes & 152 & 40.15 & 7.67 & .47 \\
& no & 231 & 40.11 & 8.13 & \\
Social Sensitivity & yes & 152 & 47.53 & 9.08 & $2.577^{*}$ \\
Social Control & no & 231 & 45.04 & 9.49 & \\
& yes & 152 & 48.59 & 8.28 & -.673 \\
& no & 231 & 49.19 & 8.71 & \\
& yes & 152 & 53.78 & 10.45 & $2.328^{*}$ \\
\hline
\end{tabular}

${ }^{*} p<.05{ }^{* *} p<.01$

\section{DISCUSSION}

\section{LONELINESS AND Social SKILlS WITH RESPECt To GENDER}

According to the research findings, loneliness levels of male students were observed to be significantly higher than loneliness levels of female students. This finding is similar to the findings of Jones, Freeman and Goswick (1981), Moraldo (1981), Wittenberg and Reis (1986), Russell, Peplau and Cutrona (1980), and Ari and Hamarta (2000).

Research findings also show that average points of emotional expressivity, emotional sensitivity, and social control subscales for female students are significantly higher than those of male students while the average emotional control points of male students are significantly higher than those of female students. The reason for this finding could be the superiority of sending emotional signals and social self-presentation of female students. The responsibility of Turkish males to control their emotional and nonverbal reactions and to suppress their emotions, which are the results of Turkish culture, could be the reason for their higher points of emotional control levels. Research findings are similar to the findings of previous studies such as those of Deniz (2002), Balci and Kalkan (2001), Riggio (1986), Friedman, Prince, Riggio, and DiMatteo (1980), and Rosenthal, Hall, DiMatteo, Rogers, and Archer (1979). 


\section{Loneliness and Social Skills with Respect to AtTachment Styles}

A significant correlation between loneliness and attachment was detected. Loneliness was found to be positively correlated to fearful, dismissing, and preoccupied attachment styles, while it was negatively correlated to the secure attachment style. These findings mean that people who have secure attachment style are less lonely than others. They have a positive view of themselves and others. This enables them to easily establish and maintain relationships and escape from loneliness. The negative views of individuals who have fearful, dismissing, and preoccupied attachment styles reduce their skills in establishing and maintaining relationships.

DiTommaso (1997) and DiTommaso et al. (2003) stated that the secure attachment style is negatively correlated to romantic and social loneliness, and other attachment styles are positively correlated to loneliness. Research findings of the study by Nurmi et al. (1997) are similar to our findings. The negative correlation between secure attachment style and loneliness level can also be found in the study by Moore and Leung (2002) which supports our findings. Additionally, some research which explains the relationship between loneliness and abstaining from social situations also explains the relationship between loneliness and the dismissing attachment style (Rook, 1984).

In terms of social skills, while the secure attachment style was found to have a significant effect on emotional expressivity and social expressivity, other attachment styles were found to have no effect on social skills. This finding means that individuals who have a secure attachment style can easily express their emotions and send verbal or nonverbal signals. This finding is also similar to the findings of DiTommaso et al. (2003). The finding of Guerrero and Jones (2003) related to secure attachment style supports our finding.

No significant relationship between attachment styles and emotional sensitivity was observed. Hence, it can be said that an individual's attachment style does not affect his/her ability to receive and interpret nonverbal communications. This finding conflicts with that by DiTommaso et al. (2003) which showed that emotional sensitivity is positively correlated to the secure attachment style and negatively correlated to the fearful attachment style. This matter may be considered as a topic for further research.

A negative relationship between social sensitivity and the secure attachment style was found. This finding shows that individuals who have a secure attachment style generally do not need to take others as a model for their social behaviors. Social sensitivity was also found to be positively correlated to the fearful and the preoccupied attachment styles. The positive relationship between social sensitivity and the preoccupied attachment style found in the current study supports the theoretical definition of the preoccupied attachment style, which states that individuals who have a preoccupied attachment style are mostly 
dependent on others for self-determination. In this study, no significant relationship between social sensitivity and the dismissing attachment style was observed. In terms of social sensitivity, our findings are similar to the findings of DiTommaso et al. (2003) and Guerrero and Jones (2003).

According to the research findings, emotional control is not significantly affected by attachment styles. This is also similar to the conclusions of DiTommaso et al. (2003). However, previous research suggests that anxious individuals tended to report inhibiting the expression of negative emotion; preoccupation, fearful avoidance, and dismissiveness are positively correlated to emotional suppression when people reported their behavior during the departure of their romantic partner; preoccupied individuals reported less emotional control than did the other three groups (Guerrero \& Jones, 2003). Research findings also showed that social control is positively correlated to the secure attachment style, negatively correlated to the fearful and preoccupied attachment styles, and not correlated to the dismissing attachment style. An individual who has a high level of social control can be seen as distant towards others and this is essentially a consequence of the dismissing and fearful attachment styles (DiTommaso et al., 2003). A similar finding suggests that fearful avoidants report the least skill in social control (Guerrero \& Jones, 2003).

\section{Loneliness and Social Skills with Respect to the Existence of a ROMANTIC RELATIONSHIP}

Research findings show that the loneliness levels and social skill levels of university students differentiate with respect to the existence of a romantic relationship. The loneliness levels of university students who do not have a romantic relationship were found to be significantly higher than the loneliness levels of other university students. Weiss (1973) stated that individuals who are unable to attach to other individuals will feel themselves lonely. The finding of our research given above confirms this statement of Weiss. This finding is also similar to the findings of Büyüksahin (2001) who stated that loneliness levels of individuals who have close relationships are lower than the loneliness levels of other individuals.

The emotional expressivity, emotional sensitivity, social expressivity, and social control points of university students who have a romantic relationship were found to be significantly higher than those of other university students. This means that the social skill levels of university students have a significant effect on their success in establishing and maintaining social communications and romantic relationships. 


\section{CONCLUSIONS}

According to the research findings, loneliness differentiates with respect to the gender of university students, and the loneliness levels of male students are significantly higher than are the loneliness levels of female students. Furthermore, while emotional expressivity, emotional sensitivity, and social control levels of female students were found to be significantly higher than those of male students, the emotional control levels of male students were found to be significantly higher than the emotional control levels of female students.

The attachment styles of students have a significant effect on their loneliness levels. While a secure attachment style affects loneliness negatively, other attachment styles affect loneliness positively. Research findings also showed that the emotional expressivity and social expressivity levels of students are affected by a secure attachments style only.

No significant effect of attachment styles on emotional sensitivity was observed. Social sensitivity was found to be negatively correlated to secure attachment style, and positively correlated to fearful and preoccupied attachment styles - while no significant relation was found between social sensitivity and the dismissing attachment style.

Attachment styles were not found to affect emotional control significantly. Social control was found to be positively correlated to secure attachment style, and negatively correlated to fearful and preoccupied attachment styles. No significant relationship between social control and dismissing attachment style was detected.

Several conclusions can be drawn by means of the romantic relationship variable. The loneliness levels of university students who have a romantic relationship were found to be significantly lower than the loneliness levels of other students. Additionally, emotional expressivity, emotional sensitivity, social expressivity, and social control points of university students who have a romantic relationship were found to be significantly higher than those of other university students.

It can be concluded from the research findings that there are significant relationships among attachment styles, social skills, and loneliness. More research is needed to generalize findings of this research. This research can be extended by including other levels of educational organizations. The relationship between attachment styles and social skills is very important in terms of training of primary caregiver(s) of 0-6 age children. It can be useful to educate adults about the development process of 0-6 age children. Since attachment and loneliness are universal concepts, cross-cultural studies may also be considered as future work. 
REFERENCES

Ari, R., \& Hamarta, E. (2000). Investigation of social skills and loneliness levels of university students with respect to their personal characteristics. Selcuk University Journal of Faculty of Education, 10, 121-134.

Bacanl, H. (1997). Self-concept in social relationships: The physiology of self monitoring. Istanbul: Turkish Ministry of National Education Publications.

Balc1, S., \& Kalkan, M (2001). Investigation of social skill levels of university students by various respects. Selcuk University Journal of Faculty of Education, 11, 76-92.

Bartholomew, K., \& Horowitz, L. M. (1991). Attachment styles among young adults: A test of a fourcategory model. Journal of Personality and Social Psychology, 61(2), 226-244.

Bowlby, J. (1979). The making and breaking of affectional bonds. London: Tavistock.

Bowlby, J. (1980). Attachment and loss: Vol. 3. Loss: Sadness and depression. London: Hogarth Press.

Büyüksahin, A. (2001). Comparison of university students with and without close relationships in terms of some psychological factors. Unpublished MSc Thesis. Ankara: Ankara University, Institute of Social Sciences.

Demir, A. (1990). Some factors that affect the loneliness levels of university students. Unpublished $\mathrm{PhD}$ Dissertation, Ankara: Hacettepe University, Institute of Social Sciences.

Deniz, E. (2002). Investigation of decision making strategies and social skills levels of university students with respect to TA-dominant ego states and some personal characteristics. Unpublished PhD Dissertation, Konya: Selcuk University, Institute of Social Sciences.

DiTommaso, E. (1997). Assessing an attachment model of loneliness: The relationship between attachment style, chronic loneliness and coping. Dean of Graduate Studies. Unpublished $\mathrm{PhD}$ Dissertation. Canada: The University Of New Brunswick.

DiTommaso, E., Brannen-McNulty, C., Ross, L., \& Burgess M. (2003). Attachment styles, social skills and loneliness in young adults. Personality and Individual Differences, 35(2), 303-312.

Friedman, H. S., Prince, L., Riggio, R., \& DiMatteo, M. (1980). Understanding and assessing nonverbal expressiveness: The affective communication test. Journal of Personality and Social Psychology, 39, 333-351.

Griffin, D., \& Bartholomew, K. (1994). Metaphysics of measurement: The case of adult attachment. In K. Bartholomew \& D. Perlman (Eds.), Advances in personal relationships, Vol. 5: Attachment processes in adulthood (pp.17-52). London: Jessica Kingsley.

Guerrero L. K., \& Jones, S. M. (2003). Differences in one's own and one's partner's perceptions of social skills as a function of attachment style. Communication Quarterly, 51 (3), 277-296

Hazan, C., \& Shaver, P. (1987). Romantic love conceptualized as an attachment process. Journal of Personality and Social Psychology, 52, 511-524.

Jones, W. H., Freemon, J. E., \& Goswick, R. A. (1981). The persistence of loneliness: Self and other determinants. Journal of Personality, 49, 27-48.

Moore, S., \& Leung, C. (2002). Young people's romantic attachment styles and their associations with well-being. Journal of Adolescence, 25, 243-255.

Moraldo, G. K. (1981). Shyness and loneliness among college men and women. Psychological Reports, 48, 885-886.

Nurmi, J., Toivonen, S., Salmela-Aro, K., \& Eronen, S. (1997). Social strategies and loneliness. Journal of Social Psychology, 137 (6), 764-778.

Peplau, L. A., \& Perlman, D. (1982). Perspectives on loneliness. In L. A. Peplau \& D. Perlman (Eds). Loneliness: A sourcebook of current theory, research and therapy. New York: Wiley Interscience.

Riggio, R. (1986). Assessment of basic social skills. Journal of Personality and Social Psychology, 51, 649-660. 
Riggio, H. R. (1999). Personality and social skill differences between adults with and without siblings. Journal of Psychology Interdisciplinary \& Applied, 133 (5), 514-521.

Rook, K. S. (1984). Promoting social bonding: Strategies for helping the lonely and socially isolated. American Psychologist, 39 (12), 1388-1407.

Rosenthal, R., Hall, J. A., DiMatteo, M. R., Rogers, P. L., \& Archer, D. (1979). Sensitivity to nonverbal communications: The PONS Test. Baltimore: The Johns Hopkins University Press.

Russell, D., Peplau, L. A., \& Cutrona, C. E. (1980). The revised UCLA Loneliness Scale: Concurrent and discriminant validity evidence. Journal of Personality and Social Psychology, 39, 472-480.

Russell, D., Peplau, L. A., \& Ferguson, M. L. (1978). Developing a measure of loneliness. Journal of Personality Assessment, 42, 290-294.

Shaver, P., \& Hazan, C. (1989). Being lonely, falling in love: Perspectives from attachment theory. In M. Hojat \& R. Crandall (Eds.), Loneliness: Theory, research and applications (pp.105-124), Newbury Park, California: Sage Publications.

Sümer, N., \& Güngör, D. (1999). Assessment of Turkish adolescence attachment styles and a crosscultural comparison. Türk Psikoloji Dergisi, 14 (43), 71-106.

Waters, E., Merrick, S., Treboux, D., Crowell, J., \& Albersheim, L. (2000). Attachment security in infancy and early adulthood: A twenty-year longitudinal study. Child Development, 71, 684-689.

Weiss, R. S. (1973). Loneliness: The experience of emotional and social isolation. Cambridge. MA: MIT Press.

Weiss, R. S. (1974). The provisions of social relationships. In Z. Rubin (Ed.), Doing unto others: Joining, molding, conforming, helping, loving (pp. 17-26). Englewood Cliffs, NJ: Prentice Hall.

Weiss, R. S. (1989). Reflections on the present state of loneliness research. In M. Hojat \& R. Crandall (Eds.), Loneliness: Theory, research and applications (pp. 51-56). Newbury Park, California: Sage Publications.

Wittenberg, M. T., \& Reis, H. T. (1986). Loneliness, social skills and social perception. Personality and Social Psychology Bulletin, 12, 121-130.

Yüksel, G. (1997). Effect of social skill education on social skill levels of university students. Unpublished PhD Dissertation, Ankara: Gazi University, Institute of Educational Sciences. 
Copyright of Social Behavior \& Personality: An International Journal is the property of Society for Personality Research and its content may not be copied or emailed to multiple sites or posted to a listserv without the copyright holder's express written permission. However, users may print, download, or email articles for individual use. 